\title{
Letrozole in advanced breast cancer: the PO25 trial
}

\author{
Henning T. Mouridsen
}

Received: 3 January 2007 / Accepted: 16 January 2007 / Published online: 27 February 2007

(C) Springer Science+Business Media B.V. 2007

\begin{abstract}
Tamoxifen has been a standard first-line endocrine therapy for post-menopausal women with hormone-responsive advanced breast cancer, but more than half of patients fail to respond and time to progression is less than 12 months in responders. The third-generation aromatase inhibitors were developed to provide more effective alternatives to tamoxifen. In the Femara Study PO25, post-menopausal women with advanced breast cancer were randomized to receive letrozole $2.5 \mathrm{mg} \quad(n=453)$ or tamoxifen $20 \mathrm{mg}$ $(n=454)$ given orally daily until progressive disease occurred. Patients were permitted to cross over to the other treatment at progression. In the primary efficacy analysis, median time to progression (TTP) was significantly longer with letrozole than with tamoxifen (9.4 months vs. 6.0 months, respectively; $P<0.0001$ ). The objective response rate (ORR) was significantly higher for letrozole than for tamoxifen (32\% vs. $21 \%$; $P=0.0002)$. Prospectively planned analyses of the intent-to-treat population showed that letrozole significantly improved overall survival (OS) compared with tamoxifen over the first 24 months of the trial. An exploratory analysis of patients, who did not cross over, indicated a median OS benefit of 14 months for letrozole compared with tamoxifen. Letrozole is the only third-generation aromatase inhibitor that has demonstrated significant improvements in ORR, TTP, and early OS.
\end{abstract}

H. T. Mouridsen ( $₫)$

Department of Oncology, Rigshospitalet, Copenhagen

University Hospital, Blegdamsvej 9, 2100 Copenhagen,

Denmark

e-mail: hmouridsen@rh.dk
Keywords Advanced breast cancer - Aromatase inhibitors · Letrozole $\cdot$ Postmenopausal $\cdot$ Tamoxifen

\section{Introduction and rationale}

The treatment goals for advanced or metastatic breast cancer (MBC) are to delay disease progression and to prolong survival $[1,2]$ and to optimize patient care in terms of ameliorating symptoms, thereby improving or maintaining quality of life [3-5]. Although treatment may include surgery and radiation therapy for the treatment of locally advanced tumors or isolated metastases, systemic therapies (endocrine, cytotoxic, biologic, and palliative) are the foundation of disease management $[6,7]$. Systemic therapy for patients with advanced breast cancer should be tailored according to specific tumor biology, particularly with respect to hormone receptor (HR) and human epidermal growth factor receptor 2 (HER2) status, the growth rate of disease, presence of visceral metastases, history of prior therapy and response, susceptibility to treatment-related toxicity, and individual patient preference [7-14]. Systemic therapy can prolong survival and enhance patient quality of life but is not curative [1]. Consequently, minimally toxic endocrine therapies are generally preferred to cytotoxic therapy as initial therapy for patients with hormone-responsive tumors [6, 15].

Since the 1980s, endocrine therapy with tamoxifen was well established as a standard first-line treatment for post-menopausal women with advanced breast cancer, even though estrogen receptor (ER) expression was not always used routinely to select patients for endocrine therapy [16-18]. The first-generation 
aromatase inhibitor aminoglutethimide or a progestin such as megestrol acetate has provided a reasonable second-line alternative [19-22]. The objective response rate (ORR) to tamoxifen was shown to be in the range of $25 \%-45 \%[16,17,19,21,23-32]$, indicating that more than half of the patients with advanced breast cancer are intrinsically resistant to tamoxifen. Furthermore, the short median time to treatment failure (TTF), in the range 6-8 months, demonstrates a relatively rapid emergence of resistance in patients initially sensitive to tamoxifen [19, 27]. Loss of ER expression appears to be the dominant mechanism of de novo resistance, and most ER/progesterone receptor negative $(\mathrm{PgR}-)$ tumors do not respond to tamoxifen [18, 33-36]. However, the majority of patients who develop acquired tamoxifen resistance still express ER at the time of progression $[37,38]$ and may respond to alternative endocrine therapies [39].

The third-generation aromatase inhibitors letrozole, anastrozole, and exemestane were developed in the search for more effective therapeutic alternatives to tamoxifen. Aromatase inhibitors prevent estrogen synthesis by potently inhibiting the aromatase enzyme, which converts androgens to estrogen [40]. Unlike tamoxifen, the aromatase inhibitors do not have any partial estrogen-agonist activity [41] and are less susceptible to the emergence of resistance associated with long-term estrogen deprivation [42]. The development and mechanism of action of aromatase inhibitors is described in detail in the article by Dr. Bhatnagar in this supplement.

\section{Studies of aromatase inhibitors in the second-line setting}

The initial randomized controlled trials of third-generation aromatase inhibitors were conducted in patients with advanced breast cancer in whom tamoxifen had failed (i.e., second-line setting). Letrozole, anastrozole, and exemestane all demonstrated evidence of clinical superiority to megestrol acetate in the secondline setting [43-47]. Thus, the individual trials demonstrate a trend or even a significant difference in favor of the third-generation aromatase inhibitors in one or more efficacy end points; in addition, the aromatase inhibitors were shown to be associated with improved tolerability versus comparator endocrine therapy in these randomized trials.

One trial demonstrated a significantly higher ORR for letrozole $(2.5 \mathrm{mg}$ dose) compared with megestrol acetate $(24 \%$ vs. $16 \%$, respectively; $P=0.04)$ and a trend toward longer time to progression (5.6 vs.
5.1 months, $P=0.07$ ) [45]. In this trial, low-dose letrozole $(0.5 \mathrm{mg})$ was associated with similar efficacy outcomes compared with megestrol acetate. However, in another similarly designed trial with letrozole versus megestrol acetate, overall response rates with the two doses of letrozole $(0.5$ and $2.5 \mathrm{mg})$ and with the comparator were similar $(21 \%, 16 \%$, and $15 \%$, respectively). In this trial, low-dose letrozole was superior to megestrol acetate in terms of time to progression (TTP) $(P=0.044)$ and survival $(P=0.053)$. Differences in the distribution of baseline variables may explain the different outcomes in the two trials in terms of the superiority of letrozole over megestrol acetate according to dose [48]. Letrozole was significantly better tolerated than megestrol acetate, specifically in terms of serious adverse experiences, discontinuation due to poor tolerability, cardiovascular side effects, and weight gain [45].

Third-generation aromatase inhibitors have demonstrated greater potency and selectivity than the firstgeneration compound aminoglutethimide [49]. Two doses of the most potent aromatase inhibitor letrozole ( $2.5 \mathrm{mg}$ and $0.5 \mathrm{mg}$ ) [49] were compared with aminoglutethimide in a randomized controlled trial in the second-line setting and demonstrated superior efficacy and improved safety [50]. The higher dose of letrozole showed a trend $(P=0.06)$ toward superior ORR (19.5\%) compared with aminoglutethimide (12.4\%). Letrozole $2.5 \mathrm{mg}$ was also significantly superior in TTP, TTF, and overall survival (OS). Fewer patients taking letrozole experienced adverse events than those taking aminoglutethimide ( $33 \%$ vs. 46\%) [50]. Letrozole has also been compared with anastrozole in a randomized, unblinded trial in the second-line setting in patients with MBC. The trial showed that letrozole was associated with a statistically higher ORR than anastrozole ( $19.1 \%$ vs. $12.3 \%$, respectively; $P=0.013)$, whereas TTP (the major end point), TTF, and clinical benefit and duration of response were similar between the two agents [51]. Both letrozole and anastrozole were well tolerated, and a similar incidence of adverse events was observed in the two groups.

These studies generated the hypothesis that letrozole might have superior efficacy to tamoxifen as first-line therapy for advanced breast cancer. A large clinical trial (Femara Study PO25) was therefore conducted to compare the efficacy and tolerability of letrozole with those of tamoxifen as first-line therapy in post-menopausal women with advanced breast cancer [52]. This review will describe the results of the PO25 trial, highlighting the evidence for the superiority of letrozole over tamoxifen as first-line endocrine therapy in this setting. 


\section{Trial design and patients}

The Femara Study PO25 was the largest phase 3 trial conducted in the advanced breast cancer setting [52, 53]. This randomized, double-blind, double-dummy trial was powered for superiority and needed to enroll approximately 900 patients to demonstrate a $20 \%$ reduction in the risk of progression with the more effective treatment. To achieve the recruitment target, the trial was conducted in 201 centers in 29 countries. Local ethics review boards approved the protocol, and all patients gave written informed consent before study enrollment.

\section{Randomized trial design}

Patients were randomized to receive letrozole $2.5 \mathrm{mg}$ or tamoxifen $20 \mathrm{mg}$ given orally daily until progressive disease occurred. Patients were permitted to cross over from 1 treatment arm to the other in a double-blind fashion if their first-line treatment was discontinued because of progressive disease or for any other reason (Fig. 1). Patients in whom endocrine therapy was discontinued were subsequently treated as clinically indicated, using chemotherapy, trastuzumab, and bisphosphonates. The crossover design was an integral part of the study, and it probably affected the assessment of OS.

\section{Patient population}

Post-menopausal women with advanced breast cancer, defined as stage IIIB locally advanced disease, locoregionally recurrent disease that was not amenable to surgery or radiotherapy, or metastatic disease, were eligible for inclusion in the trial. All patients presented with measurable or assessable tumors and were candidates for endocrine therapy. Patients had estrogen receptor-positive $(\mathrm{ER}+)$ and/or progesterone receptorpositive $(\mathrm{PgR}+)$ tumors or unknown HR status. One prior chemotherapy regimen for the treatment of metastatic disease was permitted, but recurrence during or within 12 months of adjuvant antiestrogen therapy and any prior endocrine therapy for advanced breast cancer precluded enrollment.

\section{End points}

The primary end point was TTP, defined as the interval between date of randomization and the earliest date of disease progression. Disease progression was determined on the basis of tumor progression (an increase of $25 \%$ or more in measurable lesions, an estimated increase of the same magnitude of nonmeasurable lesions, or the appearance of new lesions), treatment discontinuation with evidence of clinical deterioration due to breast cancer, death due to breast cancer, or death of unknown cause (with documented evidence of clinical deterioration due to breast cancer) while receiving treatment or within 6 weeks of discontinuation of treatment.

The secondary end points were ORR, duration of overall response, rate and duration of clinical benefit, TTF, time to response (TTR), time to chemotherapy (TTC), safety, and OS. ORR was defined as the proportion of patients who achieved a complete response (CR) or a partial response (PR), confirmed by a second evaluation 1-3 months later. The duration of overall response was defined for patients with $\mathrm{CR}$ or $\mathrm{PR}$, as the interval between date of randomization and the earliest date of disease progression. The rate of clinical benefit was defined as proportion of patients who achieved CR or PR or who stabilized (NC) for at least 24 weeks; the duration of clinical benefit was defined for patients who achieved CR or PR or NC as the interval between date of randomization and the earliest date of disease progression. TTF was defined as the interval between date of randomization and the earliest date of disease progression, withdrawal, lost to follow-up, or death. TTR was defined for CR or PR

Fig. 1 Study design

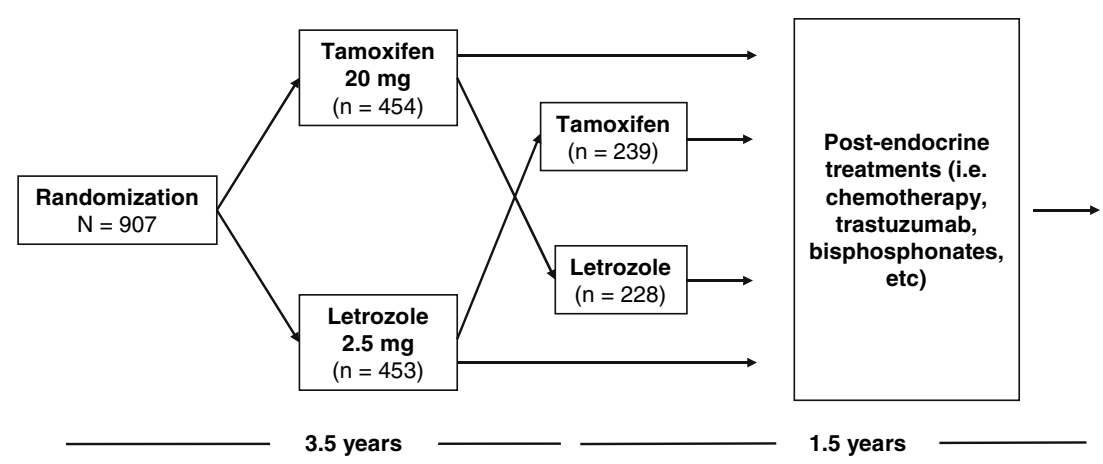


patients as the interval between randomization and the earliest documentation of response, and TTC was defined as the total duration of endocrine therapy. The duration of OS was defined as the interval between randomization and death for any reason.

Exploratory analyses of OS were performed. The first analysis included all patients with censoring at crossover, whereas the second included only patients with no crossover. The latter group predominantly comprised of patients with "nonresponsive" disease (patients who responded to first-line therapy are more likely to be crossed over later at progression), whereas the former included "nonresponsive" as well as "responsive" patients.

\section{Efficacy}

The characteristics of the 907 patients included in the intent-to-treat (ITT) population were well balanced between the letrozole and tamoxifen arms. The median age of the patients was 65 years (range 31-96 years) in the letrozole arm and 64 years (range 31-93 years) in the tamoxifen arm. Patients were predominantly white (86\%), and $92 \%$ had Karnofsky performance status (KPS) scores of $80-100$. The majority (93\%) of the study population had metastatic disease. Soft tissue lesions were the dominant metastatic site in one quarter of patients and were present in $63 \%$ and $61 \%$ of patients in the letrozole and tamoxifen arms, respectively. Bone metastases were the dominant metastatic site in approximately $30 \%$ of patients and were present in $54 \%$ and $50 \%$, respectively. Visceral metastases were the dominant site in $43 \%$ of patients in the letrozole arm and $46 \%$ of the patients in the tamoxifen arm. Most patients $(71 \%$ in the letrozole arm and $66 \%$ in the tamoxifen arm) had not received any prior chemotherapy, and few had received chemotherapy for advanced disease ( $9 \%$ and $11 \%$, respectively). The majority of patients (109 of 167) treated with adjuvant tamoxifen received at least 2 years of therapy, and the treatment-free interval between stopping adjuvant therapy and entering the study was more than 2 years in 126 of 167 patients. Of the 907 patients included in the ITT efficacy population, 467 crossed over to the other treatment arm, 75 continued on first-line therapy without progression, and the remainder terminated first-line treatment without crossover (Fig. 2).

Letrozole was superior to tamoxifen for all primary and secondary efficacy end points, including a prospectively planned survival analysis at 1- and 2-year follow-up [53].

\section{Time to progression}

In the primary efficacy analysis, the median TTP was significantly longer with letrozole than with tamoxifen

Fig. 2 Patient disposition

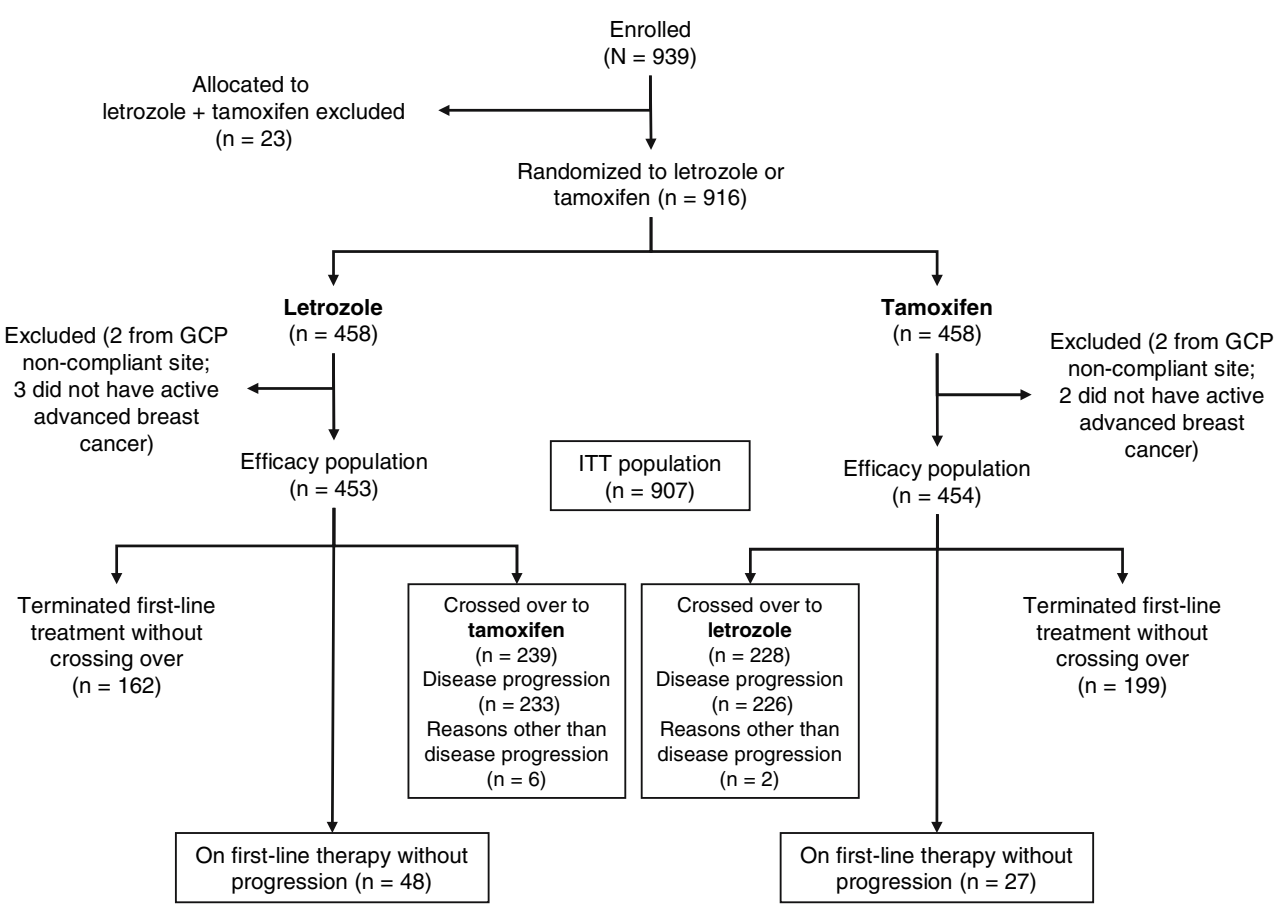




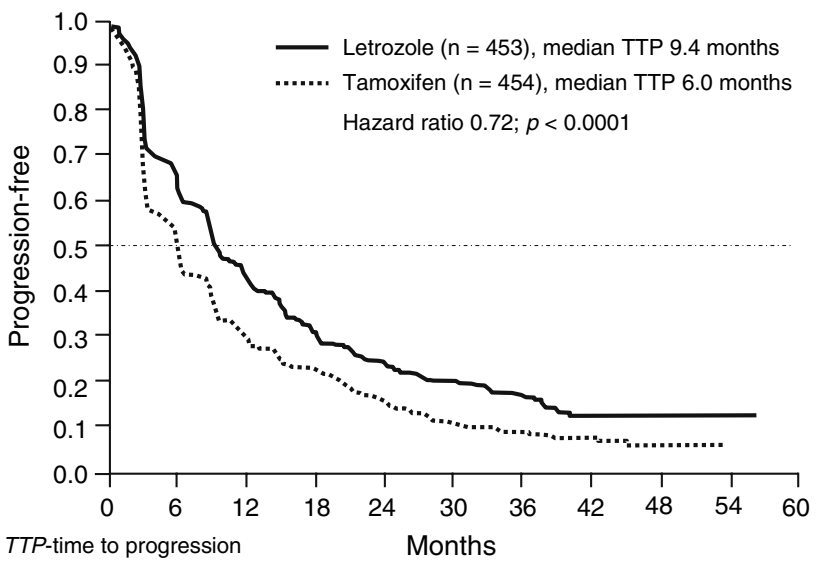

Fig. 3 Time to progression at median follow-up of 32 months for patients on first-line letrozole versus tamoxifen. Reprinted from ref. [53] with permission from the American Society of Clinical Oncology

(9.4 months vs. 6.0 months, respectively; $P<0.0001$ ) (Fig. 3) [53]. Of patients in the letrozole arm, 359 $(79 \%)$ progressed, compared with 387 (85\%) in the tamoxifen arm. The hazard ratio of 0.72 represents a $28 \%$ reduction in the risk of disease progression with letrozole $(P=0.0001)$.

The significant improvement in TTP with letrozole was confirmed in supportive multivariate analysis of prospectively defined baseline covariates, including receptor status, prior adjuvant tamoxifen therapy, and dominant site of metastatic disease [52, 54]. The analysis showed that the risk of progression was increased by the presence of either visceral or bone metastases as the dominant site of metastatic disease compared with soft tissue as dominant site. In the multivariate analysis, the significant improvement in TTP with letrozole over tamoxifen (hazard ratio $0.70 ; 95 \%$ confidence intervals $[\mathrm{CI}] 0.60,0.81 ; P=0.0001)$ was similar to the benefit observed in unadjusted analysis and was significant for each individual covariate $(P=0.0001)$ [53]. Median TTP values for letrozole and tamoxifen in the different subgroups are shown in Table 1. In patients with nonvisceral metastases, the risk for progression was $25 \%$ lower with letrozole than with tamoxifen, whereas in patients with visceral metastases, excluding the liver, the risk for progression was 34\% lower and the median TTP was almost twice as long with letrozole than with tamoxifen [54]. Although TTP was shortest for patients with liver lesions, the risk for progression was still $36 \%$ lower with letrozole than with tamoxifen in this subgroup [54].

Patients with prior adjuvant antiestrogen therapy benefited from letrozole in line with the total group, as did patients irrespective of positive or unknown receptor status of the primary tumor.

A prospectively planned analysis by patient age ( $<70$ years and $\geq 70$ years) also demonstrated that median TTP was significantly longer for letrozole than for tamoxifen in both age groups ( 8.8 months vs. 6.0 months, respectively, in the younger group and 12.2 months vs. 5.8 months in the older group) [55].

\section{Response to therapy}

Letrozole was associated with a significantly better response to therapy compared with tamoxifen $[52,53]$. ORR was significantly higher for letrozole than for tamoxifen ( $32 \%$ vs. $21 \% ; P=0.0002)$, and the corresponding rate of CRs was also significantly higher for letrozole ( $9 \%$ vs. $3 \% ; P=0.0004)$. The rate of treatment failure was lower with letrozole $(75 \%)$ than with tamoxifen (85\%), and median TTF was significantly prolonged (9.0 months vs. 5.7 months, respectively; $P<0.0001)$.
Table 1 Time to progression in different patient subgroups [57]

TTP, time to progression; CI, confidence interval; HR, hormone receptor

a Hazard ratios $<1.0$ indicate superiority for letrozole relative to tamoxifen

\begin{tabular}{llcc}
\hline Subgroup & & Letrozole & Tamoxifen \\
\hline Dominant disease site: soft tissue & $n$ & 113 & 115 \\
& Median TTP & 12.1 months & 6.4 months \\
Dominant disease site: bone & $n$ & 145 & 131 \\
& Median TTP & 9.5 months & 6.3 months \\
Dominant disease site: viscera & $n$ & 195 & 208 \\
& Median TTP & 8.3 months & 4.6 months \\
Patients who had & $n$ & 94 & 83 \\
received prior & Median TTP & 8.9 months & 5.9 months \\
antiestrogen & Hazard ratio $(95 \% \mathrm{CI})^{\mathrm{a}}$ & $0.60(0.43,0.84)$ & \\
HR-positive & $n$ & 294 & 305 \\
& Median TTP & 9.4 months & 6.0 months \\
& Hazard ratio $(95 \% \mathrm{CI})^{\mathrm{a}}$ & $0.69(0.58,0.83)$ & 149 \\
HR-unknown & $n$ & 159 & 6.0 months \\
& Median TTP & 9.2 months & \\
\hline
\end{tabular}


A supportive multivariate analysis of ORR, adjusted for the same covariates as used for the TTP analysis, showed that prior adjuvant tamoxifen, as well as visceral or bone metastases as the dominant site of metastases, significantly decreased the probability of achieving a response. The analysis also confirmed that letrozole significantly increased the probability of achieving a CR or PR compared with tamoxifen (odds ratio $1.80,95 \%$ CI $1.32-2.47 ; P=0.0002$ ) and that the superiority of letrozole remained statistically significant for each of covariates $(P=0.001)$ [52]. ORRs achieved with letrozole and tamoxifen in the different subgroups are shown in Table 2.

Overall survival

The median OS was 34 months for the letrozole group and 30 months for the tamoxifen group $(P=0.53)$. Prospectively planned analyses of the ITT population showed that letrozole significantly improved OS compared with tamoxifen over the first 24 months of the trial [53]. A Kolmogorov-Smirnov analysis to compare the survival distributions in the 2 arms [56] demonstrated a significant difference in favor of letrozole between 6 and 20 months $(P=0.003)$ and showed that the maximum difference in survival occurred at 14 months; at this time point, there were 85 deaths $(19 \%)$ in the letrozole arm compared with 132 deaths $(29 \%)$ in the tamoxifen arm. In addition, repeated log-rank tests performed at 6-month intervals indicated that survival was significantly greater with letrozole between 6 and 24 months $\quad$ (6 months: $\quad P=0.0167 ; 12$ months: $P=0.0038 ; \quad 18$ months: $\quad P=0.0010 ; \quad 24$ months: $P=0.0246$ ) (Fig. 4). The OS curves for the letrozole and tamoxifen groups crossed at around 36 months, at which time point most patients had either crossed over to the other study drug or had switched to different second-line treatments [53].

Additional exploratory analyses were therefore performed to determine the influence of crossover on OS. The crossover design was an integral part of the trial and, as with all crossover designs, had a con-
Table 2 Objective response rate in different patient subgroups [57]

ORR, objective response rate; $\mathrm{CI}$, confidence interval; $\mathrm{HR}$, hormone receptor

a Odds ratios $>1.0$ indicate superiority for letrozole relative to tamoxifen

Fig. 4 Letrozole versus tamoxifen: patients alive at 6-month intervals. Reprinted from ref. [48] with permission from Elsevier

\begin{tabular}{|c|c|c|c|}
\hline Subgroup & & Letrozole & Tamoxifen \\
\hline Dominant disease site: soft tissue & $\begin{array}{l}n \\
\text { ORR }\end{array}$ & $\begin{array}{l}113 \\
50 \%\end{array}$ & $\begin{array}{l}115 \\
34 \%\end{array}$ \\
\hline Dominant disease site: bone & $\begin{array}{l}n \\
\text { ORR }\end{array}$ & $\begin{array}{l}145 \\
23 \%\end{array}$ & $\begin{array}{l}131 \\
15 \%\end{array}$ \\
\hline Dominant disease site: viscera & $\begin{array}{l}n \\
\text { ORR }\end{array}$ & $\begin{array}{l}195 \\
28 \%\end{array}$ & $\begin{array}{l}208 \\
17 \%\end{array}$ \\
\hline $\begin{array}{l}\text { Patients who had } \\
\text { received prior } \\
\text { antiestrogen }\end{array}$ & $\begin{array}{l}n \\
\text { ORR } \\
\text { Odds ratio }(95 \% \mathrm{CI})^{\mathrm{a}}\end{array}$ & $\begin{array}{l}84 \\
26 \% \\
3.85(1.50,9.60)\end{array}$ & $\begin{array}{l}83 \\
8 \%\end{array}$ \\
\hline HR-positive & $\begin{array}{l}n \\
\text { ORR } \\
\text { Odds ratio }(95 \% \mathrm{CI})^{\mathrm{a}}\end{array}$ & $\begin{array}{l}294 \\
33 \% \\
1.78(1.20,2.60)\end{array}$ & $\begin{array}{l}305 \\
22 \%\end{array}$ \\
\hline HR-unknown & $\begin{array}{l}n \\
\text { ORR } \\
\text { Odds ratio }(95 \% \mathrm{CI})^{\mathrm{a}}\end{array}$ & $\begin{array}{l}159 \\
30 \% \\
1.79(1.10,3.00)\end{array}$ & $\begin{array}{l}149 \\
20 \%\end{array}$ \\
\hline
\end{tabular}

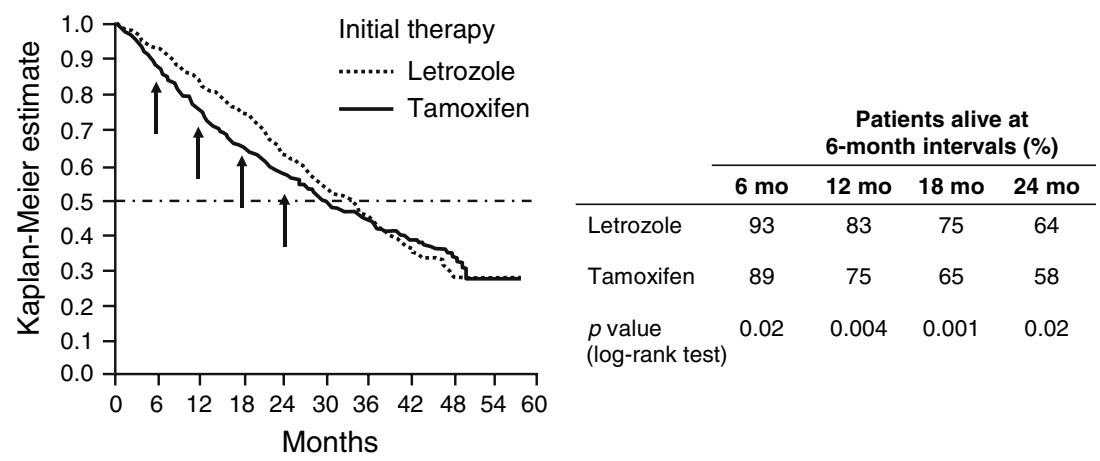


founding influence on the assessment of OS. Secondline endocrine therapy is generally less effective than first-line treatment in patients responsive to first-line therapy [16]; therefore, evaluation of OS may be impaired if the second-line treatment is actually more effective than the original first-line treatment. Furthermore, patients who are responsive to first-line therapy are more likely to cross over than are patients with nonresponsive disease who do not obtain benefit from first-line therapy.

Approximately $50 \%$ of patients crossed over to the other treatment arm (Fig. 2), and almost all of the crossovers had occurred by 36 months. The median time to crossover was longer for patients initially randomized to the letrozole arm (17 months for letrozole to tamoxifen vs. 13 months for tamoxifen to letrozole). The median OS from initial randomization, censoring time to death at crossover, was 42 months (95\% CI 36 months to not estimable) for letrozole and 30 months (95\% CI 27 to $<36$ months) for tamoxifen [53]. The superior efficacy of letrozole compared with tamoxifen was also indicated by an analysis of mortality rates and OS following crossover to the alternate treatment. The analysis showed that the mortality rate was substantially reduced ( $47 \%$ vs. $63 \%$, respectively), and OS improved in patients who crossed over to second-line letrozole compared with those who crossed over to second-line tamoxifen (31 months; 95\% CI 22-40 months vs. 19 months; 95\% CI 17-24 months, respectively) [53].

This OS analysis included all patients censored at the time of crossover (i.e., both "nonresponsive" and "responsive" patients). A second exploratory efficacy analysis of OS included only patients who did not cross over to the other arm and thus predominantly comprised patients with nonresponsive disease. This second analysis, limited to the patients who did not cross over to the alternate drug at progression, indicated a median OS benefit of 14 months for letrozole (35 months; 95\% CI 29-43 months) compared with tamoxifen (20 months; 95\% CI 16-26 months) [57].

\section{Time to chemotherapy}

Hormone therapy is the preferred treatment strategy for patients with hormone-responsive advanced breast cancer, except for those individuals with rapidly progressive disease for whom initial chemotherapy is indicated [15]. Extending the TTC is thus an important goal with hormone therapy and can maintain quality of life without having a detrimental effect on outcome. In the PO25 trial, TTC was significantly longer for patients whose initial treatment was letrozole compared with those initially randomized to receive tamoxifen (16.3 vs. 9.3 months; $P=0.005$ ).

\section{Safety}

Both letrozole and tamoxifen were well tolerated [52, 53]. The incidence of adverse effects related to study drug during first-line treatment was similar for letrozole $(38 \%)$ and tamoxifen $(37 \%)$. Hot flushes (16\% and $13 \%$, respectively), nausea ( $6 \%$ and $6 \%$, respectively), and hair thinning (5\% and $3 \%$, respectively) were the most common treatment-related adverse events reported. Bone fractures of any etiology occurred in $5.3 \%$ of patients in the letrozole group, compared with $4.2 \%$ in the tamoxifen arm, resulting in fracture rates per patient-year of treatment of 0.0427 and 0.0451 , respectively [52].

A quality-adjusted time without symptoms or toxicity (Q-TWiST) follow-up study assessed the tradeoffs between progression-free survival and toxicity in the ITT population from the PO25 trial [58]. The Q-TWiST approach quantitatively adjusts periods in which treatment toxicities or symptoms of disease progression are present to reflect the potentially reduced value for the patient; this methodology divides the survival time of the patient into various health states, assigns utility states to each, and compares treatments based on OS experience [59]. The QTWiST analysis of the clinical trial data from the PO25 trial showed that the longer TTP with letrozole compared with tamoxifen is achieved without increased time with adverse events ( 2.2 vs. 2 months, respectively), resulting in a significantly greater quality-adjusted survival for patients on letrozole (2.5-month advantage; $P<0.0001$ ) [58].

Time to worsening of KPS (decrease of $\geq 20$ points) was significantly delayed for first-line letrozole compared with first-line tamoxifen (hazard ratio 0.62; $P=0.001$ ) [54]. A subset analysis according to sites of metastases demonstrated that in patients with visceral metastases without liver involvement (mostly lung metastases), significantly fewer letrozole patients (14\%) than tamoxifen patients $(30 \%)$ experienced deteriorations in their KPS scores by $\geq 20$ points [54]. However, KPS was relatively insensitive to change in these first-line patients. 


\section{Cost-effectiveness}

In addition to its clinical superiority over tamoxifen, economic analyses have also shown that letrozole is highly cost-effective as first-line endocrine therapy in post-menopausal women with advanced breast cancer [60-62]. A follow-up analysis of patient data from the PO25 trial calculated the cost-effectiveness of first-line letrozole and tamoxifen by determining the ratio: difference in costs of breast cancer care to the difference in life years (LYs) between the two treatments [60]. The mean costs of care were $\$ 7323$ and $\$ 5468$ for letrozole and tamoxifen, respectively, representing $\$ 1855$ in incremental costs with first-line letrozole. Mean LYs to death or to the end of first- or second-line hormonal therapy were 1.54 and 1.29 for patients randomized to first-line letrozole or tamoxifen, respectively. Thus, the incremental cost per LY saved with first-line letrozole vs. tamoxifen was $\$ 7420(1855 / 0.25=7420)(2.5-97.5$ percentiles $\$ 6470-\$ 14,865)$.

In another economic analysis conducted in the United Kingdom, data from the PO25 trial were used to estimate the effectiveness of treatment [61]. The analysis showed that the mean cost of providing firstand second-line hormonal therapy was GBP4765 for first-line letrozole and GBP3418 for first-line tamoxifen (a difference of GBP1347). Since patients receiving first-line letrozole gain an additional $0.228 \mathrm{LYs}$, or 0.158 quality-adjusted life years (QALYs), the costeffectiveness analysis showed that first-line hormonal therapy with letrozole gains additional LYs at a cost of GBP5917, whereas the cost per additional QALY gained is GBP8514, which is well within the accepted cost range.

The PO25 trial data were also used in a Canadian analysis that compared the cost-effectiveness of letrozole, anastrozole, and tamoxifen [62]. The analysis showed an incremental cost per quality-adjusted progression-free year of CAN $\$ 12,500$ and CAN $\$ 19,600$ for letrozole and anastrozole, respectively, relative to tamoxifen. The authors concluded that both letrozole and anastrozole are economically acceptable alternatives to tamoxifen.

\section{Conclusions}

The Femara Study PO25 has provided evidence from a well-powered, randomized, controlled trial to show that letrozole provides a significant advantage in OS compared with tamoxifen as first-line treatment of patients with advanced breast cancer [53]. Letrozole is the only aromatase inhibitor to demonstrate consistent superiority over tamoxifen in this setting [53, 54].

Randomized first-line therapy trials of anastrozole, as part of the TARGET study [63-66], and exemestane in the EORTC study $[67,68]$ have provided evidence of clinical equivalence or superiority to tamoxifen in post-menopausal women with advanced breast cancer. However, none of these trials demonstrated statistically significant improvements in all three end points (ORR, TTP, and OS) for the aromatase inhibitor compared with tamoxifen. The PO25 study was the largest of these randomized trials in the first-line setting and demonstrated extremely strong clinical benefits, evidenced by significant superiority in TTP and ORR, with letrozole compared with tamoxifen as firstline hormone therapy. The benefits of letrozole were observed in all patient subgroups, defined by prior antiestrogen therapy, dominant site of metastatic disease, HR status (positive or unknown), and age [52-55]. Furthermore, letrozole is the only aromatase inhibitor associated with an OS advantage for the firstline setting indication at 1-year and 2-year follow-up [53]. As demonstrated in the exploratory analysis of patients who did not cross over to the alternative treatment arm, letrozole prolonged OS by 14 months compared with tamoxifen. Thus, for every 100 patients treated with hormone therapy, eight more will be alive at 1 year if they receive letrozole instead of tamoxifen.

In conclusion, third-generation aromatase inhibitors are effective and well tolerated. Letrozole should be considered as the first-line endocrine treatment in postmenopausal women with hormone-sensitive advanced or MBC. Of the available agents, only letrozole has demonstrated significant improvements in ORR, TTP, and early OS.

\section{References}

1. Fossati R, Confalonieri C, Torri V, Ghislandi E, Penna A, Pistotti V, Tinazzia A, Liberati A (1998) Cytotoxic and hormonal treatment for metastatic breast cancer: a systematic review of published randomized trials involving 31,510 women. J Clin Oncol 16:3439-3460

2. Bruzzi P, Del Mastro L, Sormani MP, Bastholt L, Danova M, Focan C, Fountzilas G, Paul J, Rosso R, Venturini M (2005) Objective response to chemotherapy as a potential surrogate end point of survival in metastatic breast cancer patients. J Clin Oncol 23:5117-5125

3. Wardley A, Davidson N, Barrett-Lee P, Hong A, Mansi J, Dodwell D, Murphy R, Mason T, Cameron D (2005) Zoledronic acid significantly improves pain scores and quality of life in breast cancer patients with bone metastases: a randomised, crossover study of community vs. hospital bisphosphonate administration. Br J Cancer 92:1869-1876 
4. Coates AS, Hürny C, Peterson HF, Bernhard J, CastiglioneGertsch M, Gelber RD, Goldhirsch A (2000) Quality-of-life scores predict outcome in metastatic but not early breast cancer. International Breast Cancer Study Group. J Clin Oncol 18:3768-3774

5. Bernhard J, Thürlimann B, Hsu Schmitz SF, CastiglioneGertsch M, Cavalli F, Morant R, Fey MF, Bonnefoi H, Goldhirsch A, Hurny C (1999) Defining clinical benefit in postmenopausal patients with breast cancer under secondline endocrine treatment: does quality of life matter? J Clin Oncol 17:1672-1679

6. NCCN-National Comprehensive Cancer Network. Breast Cancer. Clinical Practice Guidelines in Oncology-v.2.2006. http://www.nccn.org/professionals/physician_gls/PDF/breast. pdf. Cited 6 Dec 2006

7. Solomayer EF, Diel IJ, Meyberg GC, Gollan C, Bastert G (2000) Metastatic breast cancer: clinical course, prognosis and therapy related to the first site of metastasis. Breast Cancer Res Treat 59:271-278

8. Chang J, Clark GM, Allred DC, Mohsin S, Chamness G, Elledge RM (2003) Survival of patients with metastatic breast carcinoma: importance of prognostic markers of the primary tumor. Cancer 97:545-553

9. Mass RD, Press MF, Anderson S, Cobleigh MA, Vogel CL, Dybdal N, Leiberman G, Slamon DJ (2005) Evaluation of clinical outcomes according to HER2 detection by fluorescence in situ hybridization in women with metastatic breast cancer treated with trastuzumab. Clin Breast Cancer 6:240 246

10. Lipton A, Ali SM, Leitzel K, Demers L, Harvey HA, Chaudri-Ross HA, Brady C, Wyld P, Carney W (2003) Serum HER-2/neu and response to the aromatase inhibitor letrozole versus tamoxifen. J Clin Oncol 21:1967-1972

11. Cristofanilli M, Hayes DF, Budd GT, Ellis MJ, Stopeck A, Reuben JM, Doyle GV, Matera J, Allard WJ, Miller MC, Fritsche HA, Hortobagyi GN, Terstappen LW (2005) Circulating tumor cells: a novel prognostic factor for newly diagnosed metastatic breast cancer. J Clin Oncol 23:14201430, Erratum in: J Clin Oncol (2005) 23:4808

12. Goldhirsch A, Gelber RD, Price KN, Castiglione M, Coates AS, Rudenstam CM, Collins J, Lindtner J, Hacking A, Marini G et al (1994) Effect of systemic adjuvant treatment on first sites of breast cancer relapse. Lancet 343:377-381

13. Grunfeld EA, Ramirez AJ, Maher EJ, Peach D, Young T, Albery IP, Richards MA (2001) Chemotherapy for advanced breast cancer: what influences oncologists' decision-making? Br J Cancer 84:1172-1178

14. McQuellon RP, Muss HB, Hoffman SL, Russell G, Craven B, Yellen SB (1995) Patient preferences for treatment of metastatic breast cancer: a study of women with early-stage breast cancer. J Clin Oncol 13:858-868

15. Wilcken N, Hornbuckle J, Ghersi D (2003) Chemotherapy alone versus endocrine therapy alone for metastatic breast cancer. Cochrane Database Syst Rev (2): CD002747

16. Smith IE, Harris AL, Morgan M, Ford HT, Gazet JC, Harmer CL, White H, Parsons CA, Villardo A, Walsh G, McKinna JA (1981) Tamoxifen versus aminoglutethimide in advanced breast carcinoma: a randomized cross-over trial. $\mathrm{Br}$ Med J 283:1432-1434

17. Muss HB, Wells HB, Paschold EH, Black WR, Cooper MR, Capizzi RL, Christian R, Cruz JM, Jackson DV, Powell BL et al (1988) Megestrol acetate versus tamoxifen in advanced breast cancer: 5-year analysis-a phase III trial of the Piedmont Oncology Association. J Clin Oncol 6:1098-1106

18. Ingle JN, Mailliard JA, Schaid DJ, Krook JE, Gesme DH Jr, Windschitl HE, Pfeifle DM, Etzell PS, Gerstner JG, Long HJ et al (1991) A double-blind trial of tamoxifen plus prednisolone versus tamoxifen plus placebo in postmenopausal women with metastatic breast cancer. A collaborative trial of the North Central Cancer Treatment Group and Mayo Clinic. Cancer 68:34-39

19. Ingle JN, Green SJ, Ahmann DL, Edmonson JH, Nichols WC, Frytak S, Rubin J (1982) Progress report on two clinical trials in women with advanced breast cancer. Trial I: tamoxifen versus tamoxifen plus aminoglutethimide. Trial II: aminoglutethimide in patients with prior tamoxifen exposure. Cancer Res 42(8 suppl):3461s-3467s

20. Muss HB, Case LD, Atkins JN, Bearden JD 3rd, Cooper MR, Cruz JM, Jackson DV Jr, O'Rourke MA, Pavy MD, Powell BL et al (1994) Tamoxifen versus high-dose oral medroxyprogesterone acetate as initial endocrine therapy for patients with metastatic breast cancer: a Piedmont Oncology Association study. J Clin Oncol 12:1630-1638

21. Stuart NSA, Warwick J, Blackledge GRP, Spooner D, Keen C, Taylor AR, Tyrell C, Webster DJ, Earl H (1996) A randomised phase III cross-over study of tamoxifen versus megestrol acetate in advanced and recurrent breast cancer. Eur J Cancer 32A:1888-1892

22. Lundgren S, Gundersen S, Klepp R, Lønning PE, Lund E, Kvinnsland S (1989) Megestrol acetate versus aminoglutethimide for metastatic breast cancer. Breast Cancer Res Treat 14:201-206

23. Lipton A, Harvey HA, Santen RJ, Boucher A, White D, Bernath A, Dixon R, Richards G, Shafik A (1982) Randomized trial of aminoglutethimide versus tamoxifen in metastatic breast cancer. Cancer Res 42 (8 suppl):3434s3436s

24. Bratherton DG, Brown CH, Buchanan R, Hall V, Kingsley Pillers EM, Wheeler TK, Williams CJ (1984) A comparison of two doses of tamoxifen (Nolvadex) in postmenopausal women with advanced breast cancer: $10 \mathrm{mg}$ bd versus $20 \mathrm{mg}$ bd. Br J Cancer 50:199-205

25. Ingle JN, Green SJ, Ahmann DL, Long HJ, Edmonson JH, Rubin J, Chang MN, Creagan ET (1986) Randomized trial of tamoxifen alone or combined with aminoglutethimide and hydrocortisone in women with metastatic breast cancer. J Clin Oncol 4:958-964

26. Ettinger DS, Allegra J, Bertino JR, Bonomi P, Browder H, Byrne P, Carpenter J, Catalano R, Creech R, Dana B et al (1986) Megestrol acetate $\mathrm{v}$ tamoxifen in advanced breast cancer: correlation of hormone receptors and response. Semin Oncol 13(4 suppl 4):9-14

27. Ingle JN, Twito DI, Schaid DJ, Cullinan SA, Krook JE, Mailliard JA, Marschke RF, Long HJ, Gerstner JG, Windschitl HE et al (1988) Randomized clinical trial of tamoxifen alone or combined with fluoxymesterone in postmenopausal women with metastatic breast cancer. J Clin Oncol 6:825-831

28. Bonneterre J, Mauriac L, Weber B, Roche H, Fargeot $\mathrm{P}$, Tubiana-Hulin M, Sevin M, Chollet $\mathrm{P}$, Cappelaere $\mathrm{P}$ (1988) Tamoxifen plus bromocriptine versus tamoxifen plus placebo in advanced breast cancer: results of a double blind multicentre clinical trial. Eur J Cancer Clin Oncol 24:1851-1853

29. Gill PG, Gebski V, Snyder R, Burns I, Levi J, Byrne M, Coates A (1993) Randomized comparison of the effects of tamoxifen, megestrol acetate, or tamoxifen plus megestrol acetate on treatment response and survival in patients with metastatic breast cancer. Ann Oncol 4:741-744

30. Hayes DF, Van Zyl JA, Hacking A, Goedhals L, Bezwoda WR, Mailliard JA, Jones SE, Vogel CL, Berris RF, Shemano I et al (1995) Randomized comparison of tamoxifen and two 
separate doses of toremifene in postmenopausal patients with metastatic breast cancer. J Clin Oncol 13:2556-2566

31. Falkson CI, Falkson HC (1996) A randomised study of CGS 16949A (fadrozole) versus tamoxifen in previously untreated postmenopausal patients with metastatic breast cancer. Ann Oncol 7:465-469

32. Thürlimann B, Beretta K, Bacchi M, Castiglione-Gertsch M, Goldhirsch A, Jungi WF, Cavalli F, Senn HJ, Fey M, Lohnert T (1996) First-line fadrozole HCI (CGS 16949A) versus tamoxifen in postmenopausal women with advanced breast cancer. Prospective randomised trial of the Swiss Group for Clinical Cancer Research SAKK 20/88. Ann Oncol 7:471-479

33. Lippman ME, Allegra JC (1980) Quantitative estrogen receptor analyses: the response to endocrine and cytotoxic chemotherapy in human breast cancer and the disease-free interval. Cancer 46(12 suppl):2829-2834

34. Paridaens R, Sylvester RJ, Ferrazzi E, Legros N, Leclercq G, Heuson JC (1980) Clinical significance of the quantitative assessment of estrogen receptors in advanced breast cancer. Cancer 46(12 suppl):2889-2895

35. Campbell FC, Blamey RW, Elston CW, Morris AH, Nicholson RI, Griffiths K, Haybittle JL (1981) Quantitative oestradiol receptor values in primary breast cancer and response of metastases to endocrine therapy. Lancet 2:1317-1319

36. Stewart J, King R, Hayward J, Rubens R (1982) Estrogen and progesterone receptors: correlation of response rates, site and timing of receptor analysis. Breast Cancer Res Treat 2:243-250

37. Johnston SRD, Saccani-Jotti G, Smith IE, Salter J, Newby J, Coppen M, Ebbs SR, Dowsett M (1995) Changes in estrogen receptor, progesterone receptor, and $\mathrm{pS} 2$ expression in tamoxifen-resistant human breast cancer. Cancer Res 55:3331-3338

38. Gutierrez MC, Detre S, Johnston S, Mohsin SK, Shou J, Allred DC, Schiff R, Osborne CK, Dowsett M (2005) Molecular changes in tamoxifen-resistant breast cancer: relationship between estrogen receptor, HER-2, and p38 mitogen-activated protein kinase. J Clin Oncol 23:2469-2476

39. Gutierrez MC, Detre S, Johnston S, Mohsin SK, Shou J, Allred DC, Schiff R, Osborne CK, Dowsett M (2005) Molecular changes in tamoxifen-resistant breast cancer: relationship between estrogen receptor, HER-2, and p38 mitogen-activated protein kinase. J Clin Oncol 23:2469-2476

40. Bhatnagar AS, Batzl C, Hausler A, Schieweck K, Lang M, Trunet PF (1996) Pharmacology of non-steroidal aromatase inhibitors. In: Pasqualini JR, Katzenellenbogen BS (eds) Hormone-dependent cancer. Marcel Dekker, New York, pp. $155-168$

41. Yue W, Wang J, Savinov A, Brodie A (1995) Effect of aromatase inhibitors on growth of mammary tumors in a nude mouse model. Cancer Res 55:3073-3077

42. Berstein LM, Wang JP, Zheng H, Yue W, Conaway M, Santen RJ (2004) Long-term exposure to tamoxifen induces hypersensitivity to estradiol. Clin Cancer Res 10:1530-1534

43. Jonat W, Howell A, Blomqvist C, Eiermann W, Winblad G, Tyrrell C, Mauriac L, Roche H, Lundgren S, Hellmund R, Azab M (1996) A randomised trial comparing two doses of the new selective aromatase inhibitor anastrozole (Arimidex) with megestrol acetate in postmenopausal patients with advanced breast cancer. Eur J Cancer 32A:404-412

44. Buzdar AU, Jones SE, Vogel CL, Wolter J, Plourde P, Webster A; Arimidex Study Group (1997) A phase III trial comparing anastrozole (1 and 10 milligrams), a potent and selective aromatase inhibitor, with megestrol acetate in postmenopausal women with advanced breast carcinoma. Cancer 79:730-739

45. Dombernowsky P, Smith I, Falkson G, Leonard R, Panasci L, Bellmunt J, Bezwoda W, Gardin G, Gudgeon A, Morgan M, Fornasiero A, Hoffmann W, Michel J, Hatschek T, Tiabbes T, Chaudri HA, Hornberger U, Trunet PF (1998) Letrozole, a new oral aromatase inhibitor for advanced breast cancer: double-blind randomized trial showing a dose effect and improved efficacy and tolerability compared with megestrol acetate. J Clin Oncol 16:453-461

46. Kaufmann M, Bajetta E, Dirix LY, Fein LE, Jones SE, Zilembo N, Dugardyn JL, Nasurdi C, Mennel RG, Cervek J, Fowst C, Polli A, di Salle E, Arkhipov A, Piscitelli G, Miller LL, Massimini G; The Exemestane Study Group (2000) Exemestane is superior to megestrol acetate after tamoxifen failure in postmenopausal women with advanced breast cancer: results of a phase III randomized double-blind trial. J Clin Oncol 18:1399-1411

47. Buzdar A, Douma J, Davidson N, Elledge R, Morgan M, Smith R, Porter L, Nabholtz J, Xiang X, Brady C (2001) Phase III, multicenter, double-blind, randomized study of letrozole, an aromatase inhibitor, for advanced breast cancer versus megestrol acetate. J Clin Oncol 19:3357-3366

48. Mouridsen H, Gershanovich M (2003) The role of aromatase inhibitors in the treatment of metastatic breast cancer. Semin Oncol 30(4 suppl 14):33-45

49. Bhatnagar AS, Brodie AM, Long BJ, Evans DB, Miller WR (2001) Intracellular aromatase and its relevance to the pharmacological efficacy of aromatase inhibitors. J Steroid Biochem Mol Biol 76:199-202

50. Gershanovich M, Chaudri HA, Campos D, Lurie H, Bonaventura A, Jeffrey M, Buzzi F, Bodrogi I, Ludwig H, Reichardt P, O'Higgins N, Romieu G, Friedrich P, Lassus M (1998) Letrozole, a new oral aromatase inhibitor: randomised trial comparing $2.5 \mathrm{mg}$ daily, $0.5 \mathrm{mg}$ daily and aminoglutethimide in postmenopausal women with advanced breast cancer. Ann Oncol 9:639-645

51. Rose C (2003) A comparison of the efficacy of aromatase inhibitors in second-line treatment of metastatic breast cancer. Am J Clin Oncol 26:S9-S16

52. Mouridsen H, Gershanovich M, Sun Y, Perez-Carrion R, Boni C, Monnier A, Apffelstaedt J, Smith R, Sleeboom HP, Janicke F, Pluzanska A, Dank M, Becquart D, Bapsy PP, Salminen E, Snyder R, Lassus M, Verbeek JA, Staffler B, Chaudri-Ross HA, Dugan M (2001) Superior efficacy of letrozole versus tamoxifen as first-line therapy for postmenopausal women with advanced breast cancer: results of a phase III study of the International Letrozole Breast Cancer Group. J Clin Oncol 19:2596-2606, Erratum in: J Clin Oncol (2001) 19:3302

53. Mouridsen H, Gershanovich M, Sun Y, Perez-Carrion R, Boni C, Monnier A, Apffelstaedt J, Smith R, Sleeboom HP, Jaenicke F, Pluzanska A, Dank M, Becquart D, Bapsy PP, Salminen E, Snyder R, Chaudri-Ross H, Lang R, Wyld P, Bhatnagar A (2003) Phase III study of letrozole versus tamoxifen as first-line therapy of advanced breast cancer in postmenopausal women: analysis of survival and update of efficacy from the International Letrozole Breast Cancer Group. J Clin Oncol 21:2101-2109

54. Mouridsen H, Sun Y, Gershanovich M, Perez-Carrion R, Becquart D, Chaudri-Ross HA, Lang R (2004) Superiority of letrozole to tamoxifen in the first-line treatment of advanced breast cancer: evidence from metastatic subgroups and a test of functional ability. Oncologist 9:489-496

55. Mouridsen H, Chaudri-Ross HA (2004) Efficacy of first-line letrozole versus tamoxifen as a function of age in postmen- 
opausal women with advanced breast cancer. Oncologist 9:497-506

56. Schumacher M (1984) Two-sample tests of Cramér-von Mises- and Kolmogorov-Smirnov-type for randomly censored data. Int Statist Rev 52:263-281

57. Femara prescribing information (2005) Novartis

58. Irish W, Sherrill B, Cole B, Gard C, Glendenning GA, Mouridsen H (2005) Quality-adjusted survival in a crossover trial of letrozole versus tamoxifen in postmenopausal women with advanced breast cancer. Ann Oncol 16:1458-1462

59. Gelber RD, Goldhirsch A, Cavalli F; the International Breast Cancer Study Group (1991) Quality-of-life-adjusted evaluation of adjuvant therapies for operable breast cancer. Ann Intern Med 114:621-628

60. Delea T, Smith R, Karnon J (2002) Cost-effectiveness of letrozole versus tamoxifen as 1st line hormonal therapy for postmenopausal women with advanced breast cancer: the US perspective. Program and abstracts of the 25th Annual San Antonio Breast Cancer Symposium; December 11-14, 2002; San Antonio, Texas. Breast Cancer Res Treat 76(suppl 1):S136, Abstract 542

61. Karnon J, Johnston SR, Jones T, Glendenning A (2003) A trial-based cost-effectiveness analysis of letrozole followed by tamoxifen versus tamoxifen followed by letrozole for postmenopausal advanced breast cancer. Ann Oncol 14:1629-1633

62. Dranitsaris G, Verma S, Trudeau M (2003) Cost utility analysis of first-line hormonal therapy in advanced breast cancer: comparison of two aromatase inhibitors to tamoxifen. Am J Clin Oncol 26:289-296

63. Bonneterre J, Buzdar A, Nabholtz JM, Robertson JF, Thurlimann B, von Euler M, Sahmoud T, Webster A, Steinberg M; Arimidex Writing Committee; Investigators Committee Members (2001) Anastrozole is superior to tamoxifen as first-line therapy in hormone receptor positive advanced breast carcinoma. Cancer 92:2247-2258
64. Nabholtz JM, Bonneterre J, Buzdar A, Robertson JF, Thurlimann B (2003) Anastrozole (Arimidex) versus tamoxifen as first-line therapy for advanced breast cancer in postmenopausal women: survival analysis and updated safety results. Eur J Cancer 39:1684-1689

65. Milla-Santos A, Milla L, Portella J, Rallo L, Pons M, Rodes E, Casanovas J, Puig-Gali M (2003) Anastrozole versus tamoxifen as first-line therapy in postmenopausal patients with hormone-dependent advanced breast cancer: a prospective, randomized, phase III study. Am J Clin Oncol 26:317-322

66. Thürlimann B, Hess D, Köberle D, Senn I, Ballabeni P, Pagani O, Perey L, Aebi S, Rochlitz C, Goldhirsch A (2004) Anastrozole ('Arimidex') versus tamoxifen as first-line therapy in postmenopausal women with advanced breast cancer: results of the double-blind cross-over SAKK trial 21/ 95-a sub-study of the TARGET (Tamoxifen or 'Arimidex' Randomized Group Efficacy and Tolerability) trial. Breast Cancer Res Treat 85:247-254

67. Paridaens R, Dirix L, Lohrisch C, Beex L, Nooij M, Cameron D, Biganzoli L, Cufer T, Duchateau L, Hamilton A, Lobelle JP, Piccart M (2003) European Organization for the Research, Treatment of Cancer (EORTC)- Investigational Drug Branch for Breast Cancer (IDBBC)Mature results of a randomized phase II multicenter study of exemestane versus tamoxifen as first-line hormone therapy for postmenopausal women with metastatic breast cancer. Ann Oncol 14:13911398

68. Paridaens R, Therasse P, Dirix L, Beex L, Piccart M, Cameron D, Cufer T, Roozendaal K, Nooij M, Mattiacci MR (2004) First line hormonal treatment (HT) for metastatic breast cancer (MBC) with exemestane (E) or tamoxifen (T) in postmenopausal patients (pts) - a randomized phase III trial of the EORTC Breast Group. J Clin Oncol 22(14S):515 